\title{
How do vegetable oils (hazelnut and canola) affect the reproductive system in male rats?
}

\author{
Bülent Kati ${ }^{1}$, Fatih Oguz ${ }^{2}$, Ismet Yilmaz ${ }^{3}$, Ender Akdemir ${ }^{4}$, Ramazan Altintas ${ }^{2}$, Nusret Akpolat ${ }^{5}$, \\ Mehmet Cagatay Taskapan ${ }^{6}$ \\ ${ }^{1}$ Harran University, Faculty of Medicine, Urology Department, Sanliurfa, Turkey; \\ ${ }^{2}$ Inonu University, Faculty of Medicine, Urology Department, Malatya, Turkey; \\ ${ }^{3}$ Inonu University, Faculty of Pharmacy, Pharmacology Department, Malatya, Turkey; \\ ${ }^{4}$ Lokman Hekim Hospital, Urology Clinic, Van, Turkey; \\ ${ }^{5}$ Inonu University, Faculty of Medicine, Pathology Department, Malatya, Turkey; \\ ${ }^{6}$ Inonu University, Faculty of Medicine, Medical Biochemistry Department, Malatya, Turkey. \\ Source(s) of Support No: This study was supported by Inonu University, Scientific Research Projects no: 2011/152 \\ Presentation at a Meeting: This work is presented in EAU 8th South Eastern European Meeting held in Sofia on 26 - 27 October 2012
}

\begin{abstract}
Summary Objective: Vegetable oils have an important place in our daily diet. This study starts from this point to investigate the effects of canola oil and hazelnut oil in the male reproductive system in rats.

Material and methods: 30 male rats were used in this 16-week study. The animals were divided into three groups: the animals in group I served as the control group, while the animals in group II and group III were fed with hazelnut and canola oil, respectively. The testes of all rats were excised for histopathologic evaluation and immunohistochemical (IHC) evaluation with a standard method. Blood samples were obtained for determination of serum hormone levels.

Results: No significant differences were noted with respect to behavior or weight among the three groups. Rats in the canola oil group (group III) had higher luteinizing hormone (LH) and higher testosterone levels than rats in the control group. Rats who received hazelnut oil (group II) exhibited similar findings, with these levels being higher than they were in the control group. No statistical differences were shown for histopathology or IHC testosterone antibody levels across all treatment groups. Conclussion: Canola oil was shown to have a greater effect on serum LH and testosterone compared to the control group and the group fed with hazelnut oil. Further investigation is required into how these oils affect serum hormone and sperm activity.
\end{abstract}

KEY WORDS: Canola oil; Hazelnut oil; Reproductive system; Testosteron.

Submitted 21 February 2018; 24 February 2018

\section{INTRODUCTION}

Vegetable oils have an important place in our daily diet. Commonly used sunflower and olive oil have been widely used since long time. In recent times it has been able to meet our everyday needs in hazelnut oil and canola oil (rapeseed oil), which are increasingly used in areas where they are particularly grown.

Canola is a plant with bright yellow flowers that belongs to the Brassicaceae family. Originally from the Mediterranean area and Northern Europe, B. napus is commonly known as rapeseed, and was identified in
2000 BC as a high-erucic acid crop (1). The oil from rapeseed contained $>40 \%$ erucic acid, and hesitation existed about this high acid content (as observed in animal studies). High-erucic acid rapeseed oil used to be produced in North America solely in small quantities for industrial, nonfood use (2-3). However, in 1976, Canadian scientists were able to improve the quality of previous cultivars of rapeseed by growing the plant traditionally, yielding a conversion that allowed commercial consumption In 1979, Canada registered the word "canola" to describe a new seed found to yield an oil; this oil included a smaller amount of erucic acid and glucosinolates. Inherently, canola has specific cut-of levels of erucic acid $(<2 \%)$ and glucosinolates $(<30 \mathrm{umol} / \mathrm{g}$ ) for consumption both in humans and in animals (4).

In 1985, the United States Food and Drug Administration (FDA) accepted canola oil as "generally recognized as safe" (GRAS) as a dietary component (5). Canola has become one of the most important oilseed crops worldwide over the past 40 years; currently, canola oil is the third-largest vegetable oil by volume, after palm and soybean oil (3). hazelnut (Corylus avellana L.) is a well-recognized tree nut worldwide. Hazelnuts are mainly produced in Turkey, Italy, Spain, the USA, Portugal and France. Hazelnut oil includes a high amount of both monounsaturated and polyunsaturated fatty acids as well as tocopherols (6).

Hazelnut oil contains 74.2\%-83.1\% oleic acid and linoleic acid. Therefore, the incorporation of hazelnut oil in meat products may have favourable efects on the health of consumers (7). Oils have an important place in the structure of the reproductive hormone system. The main hormones of the male reproductive system are mainly testosterone with follicle stimulating hormone (FSH) and luteinizing hormone (LH).

There are very few studies on the effects of these oils on the male reproductive system. Because of that; the aim of our study is to investigate the effects of canola oil and hazelnut oil on the male reproductive system, with a focus on evaluating the effects on serum hormone levels and testis histopathology. 


\section{Materials AND Methods}

\section{The selection and preparation of animals}

In this study, 30 four-month-old Sprague-Dawley rats were used. Inonu University Faculty of Medicine, Experimental Animal Research and Production Center provided the rats for study subjects. During the four-month study period, the average weight of the rats was $236.71 \pm$ 19.18 gr. The study was executed according to the rules of the National Health Institute at Inonu University Experimental Research Laboratory, and was performed with the consent of the Animals Ethics Committee of the Inonu University Faculty of Medicine Ethics Committee (2011/05/18). Animals were sheltered in groups of five in standard-sized ( 40 by $60 \mathrm{~cm}$ ) cages. The subjects were given 7 days to adapt to their new environment, then separated into 3 groups of 10 rats. Specially prepared hazelnut oil (12\% concentration) and canola oil ( $12 \%$ concentration also), along with the standard food containing dry pellets and tap water, was used as the diet. Indoor lighting was tuned for $12 \mathrm{~h}$ of light and $12 \mathrm{~h}$ of darkness. Heat and moisture were set to $22^{\circ} \mathrm{C}$ $\pm 2^{\circ} \mathrm{C}$ and $50 \% \pm 10 \%$, respectively.

\section{Preparations for the experiment}

After the animals were separated into groups, each group was divided into half and sheltered in 2 separate cages. Any additional process was applied to the first group (Group 1); the second group was fed with the $12 \%$ hazelnut oil added to the foodoil (Group 2). The third group was fed with food that included 12\% canola oil (Group 3).

External factors often have an impact on testicular functioning. The photoperiod is one of these factors: long photoperiods increase testicular functioning, while short periods reduce it (8). In order to avoid any morphological changes among the groups caused by the various light amounts, all rats were exposed to the rotating 12-h light/12-h dark environment in the lab. Reproduction of sperm gradually increases up to the $75^{\text {th }}$ day and the testicular weight increases up to the 100th day. When the first spermatozoa were found at the epididymis tail, about when the rats were 50 days old, they were considered adult (mature) (9). All of the rats used in our experiment were fed for approximately 4 months so that they would become 6-month-old adults and have the highest sperma reproduction. The intent in this design was to eliminate the variance in the sperma reproduction and the epididymal spermatozoa number caused by age.

\section{Preparation of the food}

As in the previous studies, the food was prepared considering the daily oil need. Pellet food was supplemented with the $12 \%$ oil (canola or hazelnut) (8-10). It was used to feed rats after the addition of appropriate fat to the amount of feed and control of homogenous distribution. The total absorption was ensured and, after a checking process, daily food of 18-24 g/rat was placed into the food reservoir. In order to keep the food fresh, a small amount of new food was prepared every week and the drinking water was provided via fresh tapwater adlibitum.

\section{Biochemical method of analysis}

The blood taken for the biochemical analysis was put into the tubes and centrifuged at $3500 \mathrm{rpm}$ for 15 minutes. The obtained serum was put into separate tubes and numbered for use with each group. Serum samples were evaluated using previously provided ELISA kits specific for rats that measured FSH (Cusabio Biotech Co., Ltd), LH (Cusabio Biotech Co., Ltd), and Testosterone (DRG International, Inc, United States) with the Basic Radim Immunoassay Operator (BRIO) (Radim spa, Pomezia, Italy) device.

\section{Histopathological}

\section{and immunohistochemical research method}

After separation by surgical dissection, the testicles were placed in Bouin's fixative for histopathological evaluation. The testis tissue was chopped with 2-mm apertures using microtome knives; routine tissue observation was practiced by sectioning one slice. Five-micron sections were derived from the paraffin-embedded blocks formed from tissue samples. After the process of deparaffinization, the sections were dyed with hematoxylin-eosin (HE). In the course of histopathological evaluation, the architectural structure was examined by the help of magnifying method beforehand. Subsequently, the size and the number of the seminiferous tubules, the thickness of the tubule basal membranes, the relative share and types of germ cells in the seminiferous germs, the degree of interstitial fibrosis, and the existence of the Leydig cells are evaluated in the course of a general examination of the testis cross-section. The evaluation was standardized by using the quantitative Clinical Scoring Method of 1 to 10 for each seminiferous tubule as suggested by Johnsen (11). Four-micron sections were obtained and placed onto polysine slides forimmunohistochemical dyeing, which was performed automatically using the Lecia Bond Max (Leica Microsystems Inc. U.S.A) device. Testosterone primary antibody (GeneTex, USA) was used as the primary antibody. The strength of the testosterone antibody dyeing was evaluated as a semi-quantitative method; the absence of dye was assigned zero points, while the most powerful dyeing was assigned a score of 3 points.

\section{Statistical method of analysis}

SPSS 15.0 for Windows (SPSS Inc., Chicago, Illinois) was used for statistical analysis. The Kolmogorov-Smirnov test was used to measure the correspondence of the different parameters and the normal distribution curve. A correspondence was observed between the LH, testosterone, and Johnsen scores as well as between the rats' pre-experimental and post-experimental testicular weights and the normal distribution curve $(\mathrm{P}>0.05)$. On the other hand, no correspondence existed between the FSH hormone distribution and the normal distrubtion curve $(\mathrm{P}<0.05)$. The Kruskal-Wallis, one-way analysis of variance (ANOVA), and post-hoc Tukey tests were used for statistical analyses in the groups that corresponded with the normal distribution curve. $\mathrm{P}<0.05$ was assumed to be significant for all evaluations. Values are given as average \pm standard deviation (mean $\pm \mathrm{SD}$ ).

\section{Results}

All of the rats were kept alive till the end of the experiment. Rats' pre-experiment and post-experiment (afer 16 


\begin{tabular}{|lcccc|}
\hline Groups $\rightarrow$ & $\begin{array}{c}\text { Control group } \\
\text { A0 } \pm \text { SS }\end{array}$ & $\begin{array}{c}\text { Hazelnut group } \\
\text { A0 } \pm \text { SS }\end{array}$ & $\begin{array}{c}\text { Canola group } \\
\text { A0 } \pm \text { SS }\end{array}$ & P \\
\hline Pre-experiment average weight (g) & $247.2 \pm 23.10$ & $228.10 \pm 34.00$ & $252.50 \pm 50.46$ & 0.327 \\
\hline Post-experiment average weight (g) & $325.0 \pm 32.47$ & $316.00 \pm 27.39$ & $345.50 \pm 43.19$ & 0.177 \\
\hline
\end{tabular}

\begin{tabular}{|lccc|}
\hline Groups $\downarrow$ hormones $\rightarrow$ & $\begin{array}{c}\text { LH (mIU/ml) } \\
\text { A0 } \pm \text { SS }\end{array}$ & $\begin{array}{c}\text { Testosterone }(\mathbf{n g} / \mathbf{m l}) \\
\text { A0 } \pm \text { SS }\end{array}$ & $\begin{array}{c}\text { FSH } \\
\text { (Min-Med-Max) }\end{array}$ \\
\hline Control & $10.86 \pm 5.47$ & $1.29 \pm 0.45$ & $12.97-26.38-77.24$ \\
\hline Hazelnut oil & $13.68 \pm 3.99$ & $1.88 \pm 0.68$ & $21.74-30.90-38.44$ \\
\hline Canola oil & $14.95 \pm 4.55$ & $2.53 \pm 0.74 *$ & $19.06-31.91-9.33$ \\
\hline
\end{tabular}

\section{Table 2.}

Average values of serum hormone $\mathrm{LH}$ and testosterone * $(P=0.001)$.

\begin{tabular}{|lc}
\hline Groups & Johnsen Score Averages $(\mathbf{A O} \pm \mathbf{S S})$ \\
\hline Control Group & $9.37 \pm 0.27$ \\
\hline Hazelnut Group & $9.21 \pm 0.31$ \\
\hline Canola Group & $9.26 \pm 0.20$ \\
\hline Total & $9.28 \pm 0.25$
\end{tabular}

weeks of feeding) average weights are given in Table 1. No variance existed between the groups' inital weights or with these weights during and at the end of the experiment $(\mathrm{P}>0.05)$.

The average wet weight of the removed testicles was measured as $1.37 \pm 0.80 \mathrm{~g}$ for the control group, $1.34 \pm$ $0.13 \mathrm{~g}$ for the hazelnut oil group, and $1.48 \pm 0.21 \mathrm{~g}$ for the canola oil group; there was no significant difference between any 2 of the 3 groups for this parameter $(\mathrm{P}=$ 0.103). Furthermore, no signficant statistical difference existed in the levels of serum FSH among the groups (P $>0.05)$ (Table 2).

The levels of serum LH for rats fed with either hazelnut or canola oil did increase, but this increase was not statistically significant $(P>0.05)$. When the levels of serum testostosterone of the 3 groups were compared, there was a statistically significant increase in the canola group $(\mathrm{P}<0.05)$. The slight increase in the hazelnut group was not significant $(\mathrm{P}>0.05)$ (Table 2).

\section{Histological examination of the testis}

The testis were removed for histopathological analysis
Table 3.

Johnsen Testicle Biopsy Scores for each group and group averages $(P=0.362)$. and preserved within the 10\% Bouin's fixative. The testicular parenchyma of the rats (covered by tunica albuginea, Leydig cells, and interstital connective tissues) were examined in the seminiferous tubules and interstitial. In the histopathological analysis, 10 cross-cut seminiferous tubules were randomly scored 1 to 10 for each rat testicle according to Johnsen scoring criteria. After that, the average value for each rat was calculated, with total group scores and averages obtained (Table 3).

No significant difference was found among the Johnsen score averages $(P>0.05)$. Furthermore, no significant difference existed between the immunohistochemical dyeing strength of total tissue testostosterone antibody of the 3 groups (Figure 1).

\section{Discussion}

Oils are one of the most significant nutrients in that they have essential roles in the human diet and conduct vital activity in the body. The positive or adverse effects of canola and hazelnut oil on the body have not been precisely determined, although their consumption have

Figure 1.

Sample of interstisial painted testosterone antibody group and scores.

a) Immunohistochemical staning intensity canola oil group 20X (Score 3).

b) Immunohistochemical staning intensity hazelnut oil group 40X (Score 2).

c) Immunohistochemical staning intensity control group 20X (Score 1).

a.

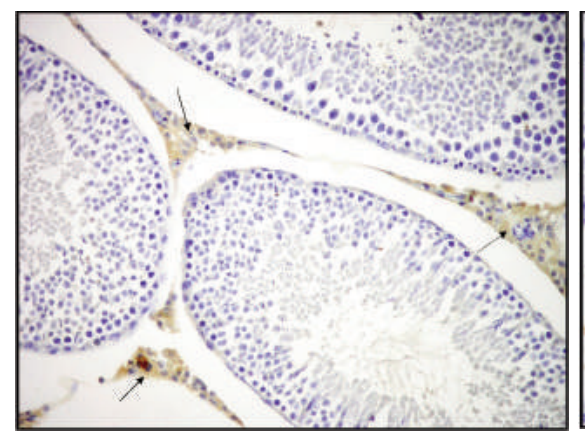

b.

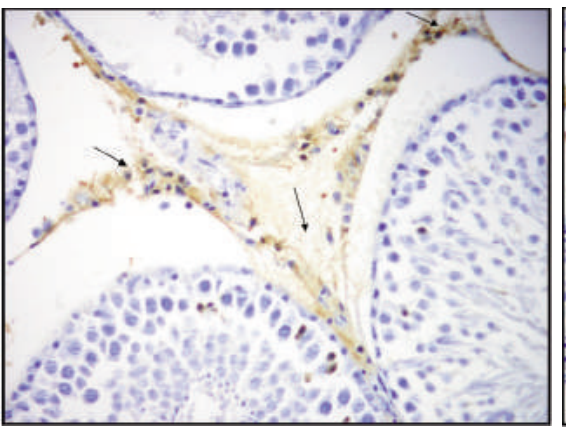

c.

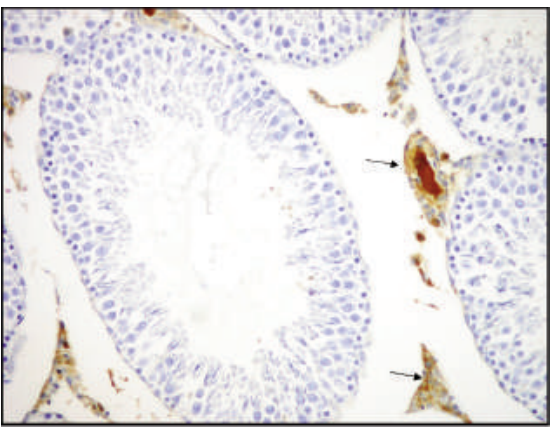


been continuously increasing in people's diets worldwide. Limited and not conclusive scientific evidence would suggest some benefit for canola oil consumption, but results from studies implementing diets containing canola oil in experimental animal models have provided us with conflicting data (10-12).

A study by Okuyama and colleagues using steroid hormones, canola and soybean oils for a 3-month period in hypertensive rats who were prone to stroke compared various elements in the rats at the end of the 3-month period, although they did not evaluate the impact of the 2 oils on the reproductive system. As a result, while the testostosterone values measured in the testicles of rats in the canola group were found to be low compared to those in the soybean group, corticosteroid and estradiol levels in the tissues demonstrated no significant difference. This difference was assumed to arise from a pathophysiology found in rats with hypertension (13). In our study, serum testosterone level increased while testosterone antibody values measured in the test were similar to the control group.

Multiple other studies exist on the effects of canola and other oils over periods ranging from 3 to 7 months. Infants fed with and without canola oil from the ages of 4 weeks to 7 months did not exhibit significant differences in height and length based on whether they consumed the oil as part of their diets (14). Similarly, in our study, weight difference was not shown in rats fed with canola oil and hazelnut oil after 4 months period.

de Almeida and colleagues evaluated the effects of a diet containing canola oil on the morphology of seminiferous tubules of young rats (15).

With evaluation of FSH, LH, and testosterone levels, significant and important information was found in terms of the determination of potential malfunctioning of the reproduction pathophysiology and the conditions of the hypothalamus-hypophyseal axis.

In our study, serum testostosterone levels in the groups receiving canola oil were higher compared to the control group $(\mathrm{P}<0.05)$. Higher levels were also found in the hazelnut group, although it was not statistically significant compared to the control group ( $\mathrm{P}>0.05)$.

No significant differences were found among the 3 groups in terms of testicular and body weight $(\mathrm{P}>0.05)$. FSH, prompted by the hypothalamus and released by the anterior pituitary gland, stimulates sertoli cells in the seminiferous tubules, speeding up sperm production of spermatids. Furthermore, it was effective in the development and maintenance of FSH sufficent testicular function in men. Within our study; no significant difference was found among the FSH values of the 3 groups ( $\mathrm{P}>$ 0.05).

LH, prompted by the hypothalamus (GnRH) and released by the anterior pituitary gland, stimulates the release of testostosterone in the interstitial Leydig cells. In our study, LH levels in the hazelnut and canola oil groups were found to be higher compared to the control group, although it was not assumed to be statistically significant $(\mathrm{P}>0.05)$. These results can be attributed to the assumption that these kinds of oils can enhance the stimulation of GnRH via the effects from the hypothalamus or that the oils can generate a slight LH stimulus by directly influencing the anterior pituitary gland. The increased level of testostosterone, especially in the canola group fed with the oils supplied with direct LH, indicates that the results may be explained by the actions of the hypothalamus-hypophyseal axis. New experimental studies are needed to fully understand the effects of the hypothalamus-hypophyseal way. The effects of testosterone on erectile dysfunction and libido indicated that testostosterone has a considerable contribution to maintenance of libido and sexual function (16). The fact that these oils have no significant effect on FSH compared to the control group increases the probability that these hormones are more effective in exerting their effects coming from the hypophysis as opposed to the hypothalamus. There are not many publications examining the effects of these oils on the reproductive system.

The effects of hazelnut and canola oil on testicle histopathology were not indicated beforehand.

Histopathologic examination of the 3 groups' testicular tissue did not reveal significant differences according to evaluation using Johnsen scoring $(\mathrm{P}>0.05)$.

Thus, no pathological adverse events related to use of these everyday oils in the diet were shown in this study. Furthermore, no statistically significant differences between the 3 groups were revealed as a result of the semi-quantitative immunohistochemical evaluation of testicle-tissue dyeing intensity $(\mathrm{P}>0.05)$.

\section{Conclusion}

The effects of vegetable oils, which we often use in our daily life, on the reproductive system can be affected by various mechanisms by affecting the hormones. Additional studies are needed for the determination of the exact effect of this condition on the tissues and its influence on spermiogenesis.

\section{ACKNOWLEDGMENTS}

We thank to the biologist Fatma Ozyalin for his assistance in the care and application of the ELISA kits used in this study.

\section{References}

1. Australian Government Department of Health and Aging Office of the Gene Technology Regulator. The Biology of Brassica napus L. (Canola).Version 2: 2008.

http://www.ogtr.gov.au/internet/ogtr/publishing.nsf/content/canola3/\$FILE/biologycanola08_2.pdf

2. Dupont J, White PJ, Johnston KM, et al. Food safety and health effects of canola oil. J Am Coll Nutr. 1989; 8:360-375.

3- United States Department of Agriculture. Economic Research Service - Canola. https://www.ers.usda.gov/topics/crops/soybeansoil-crops/canola.aspx 2017.

4. Mag T. Canola oil processing in Canada. J Am Oil Chem Soc. 1983; 60:380-384.

5. Lin L, Allemekinders H, Dansby A, et al. Evidence of health benefits of canola oil. Nutr Rev. 2013; 71:370-85.

6. Ozdemir M, Ackurt F, Kaplan M, et al. Evaluation of new 
Turkish hybrid hazelnut (Corylus avellana L.) varieties; fatty acid composition, a-tocopherol content, mineral composition and stability. Food Chem. 2001; 73:411-415.

7. Ozdemir, F. Akincl, I. Physical and nutritional properties of four major commercial Turkish hazelnut varieties. J Food Eng, 2004; 63:341-347.

8. Kus I, Songur A, Ozogul C, et al. Effects of photoperiod on the ultrastructure of Leydig cells in rat. Arch Androl. 2004; 50:193-200.

9. Robb GW, Amann RP, Killian GJ. Daily sperm production and epididymal sperm reserves of pubertal and adult rats. J Reprod Fertil. 1978; 54:103-7.

10. Cai J, Jang JY, Kim J, et al. Comparative Effects of Plant Oils on the Cerebral Hemorrhage in Stroke-Prone Spontaneously Hypertensive Rats. Nutr Neurosci. 2014; 19:318-326.

11. Johnsen SG. Testicular biopsy score count-method for registration of spermatogenesis in human testes: Normal values and results in 335 hypogonadal males. Hormones. 1970; 1:2-25.
12. Junker R, Kratz M, Neufeld M, et al. Effects of diets containing olive oil, sunflower oil, or rapeseed oil on the hemostatic system. Thromb Haemost. 2001; 85:280-6.

13. Okuyama H, Ohara N, Tatematsu K, et al.Testosterone-lowering activity of canola and hydrogenated soybean oil in the stroke-prone spontaneously hypertensive rat. J Toxicol Sci. 2010; 35:743-7.

14. Rzehak P, Koletzko S, Koletzko B, et al. GINI Study Group. Growth of infants fed formula rich in canola oil (low erucic acid rapeseed oil). Clin Nutr. 2011; 30:339-45

15. Furriel Gomes de Almeida A, Soares da Costa CA, Gaspar de Moura E, et al. Effects of soybean or canola oil intake on seminiferous tubules structure in young rats. Nutr Hosp. 2012; 27:1668-9.

16. Isidori AM, Giannetta E, Greco EA, et al. Effects of testosterone on body composition, bone metabolism and serum lipid profile in middle-aged men: a metaanalysis. Clin Endocrinol (Oxf). 2005; 63:280-293.

\section{Correspondence}

Bülent Kati, MD, Assistant Professor of Urology

bulentkati@harran.edu.tr

Department of Urology, Harran University, Faculty of Urology

63300, Sanliurfa, Turke

Fatih Oguz, MD

foguz@hotmail.com

Inonu University, Turgut Ozal Medical Center, Urology, Malatya 44100

Turkey

Ismet Yilmaz, MD

ismetyilmaz44@hotmail.com

Inonu University, Faculty of Pharmacy,, Malatya 44100 Turkey

Ender Akdemir, MD

ender_dr@yahoo.com

Lokman Hekim Hospital, Urology Clinic, Van, 65100 Turkey

Ramazan Altintas, $M D$

ramazan449@yahoo.com

Inonu University, Turgut Ozal Medical Center, Urology, Malatya 44100

Turkey

Nusret Akpolat, MD

nusretakpolat@hotmail.com

Inonu University, Turgut Ozal Medical Center, Pathology, Malatya 44100

Turkey

Mehmet Cagatay Taskapan, MD

mctaskapan@hotmail.com

Inonu University, Turgut Ozal Medical Center, Biochemistry Malatya 44100

Turkey 